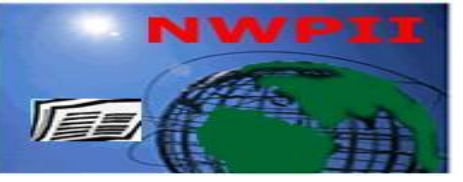

American Journal of Biomedical Sciences

ISSN: 1937-9080

nwpii.com/ajbms

\title{
Anti-inflammatory and Anti-arthritic Effects of a Novel Leflunomide Analogue, UTL-5b (GBL-5b)
}

\author{
Jiajiu Shaw ${ }^{1}$, Ben Chen ${ }^{2}$, Paul Wooley ${ }^{2}$, Wen-Hsin Huang ${ }^{3}$, An-Rong Lee ${ }^{3}$ and Dustin Zeng ${ }^{4}$ \\ ${ }^{1}$ Unitech Pharmaceuticals, Inc., Ann Arbor, MI 48108, USA \\ ${ }^{2}$ Department of Internal Medicine, Wayne State University School of Medicine, Detroit, MI 48201, USA \\ ${ }^{3}$ School of Pharmacy, National Defense Medical Center, Taipei, Taiwan \\ ${ }^{4}$ GeneBlue Corporation, San Gabriel, CA 91776, USA \\ *Corresponding author \\ Dr. Jiajiu Shaw \\ $21^{\text {st }}$ Century Therapeutics, Inc. \\ Shelby Township, MI 48316 \\ USA \\ E-mail: jiajiushaw@gmail.com
}

\begin{tabular}{l|l|l} 
Received: 2 September 2010; & Revised: 18 September 2010; & Accepted: 29 September 2010
\end{tabular}

\begin{abstract}
Rheumatoid arthritis (RA) is a common disease characterized by chronic inflammation and irreversible destruction of articular cartilage and bone. In this report, we examined the anti-inflammatory and antiarthritic effects of a novel leflunomide analogue, UTL-5b (also known as GBL-5b), for potential RA treatment. Using a carrageenan-induced edema study in rats, UTL-5b exhibited a better anti-inflammatory effect as compared with leflunomide and its metabolite. The chronic efficacy of UTL-5b was examined using type II collagen-induced arthritis (CIA) mouse model. UTL-5b exerted an anti-arthritic effect in a dosedependant manner with mice given $30 \mathrm{mg} / \mathrm{kg}$ exhibiting amelioration of disease early in the trial, but losing statistical significance over time. In contrast, mice treated with $60 \mathrm{mg} / \mathrm{kg}$ showed reduced clinical disease parameters early in the trial and these effects were sustained over the ten week trial period. Mechanistic studies indicate that UTL-5b is an inhibitor of TNF- $\alpha$ production in vivo. Oral administration of UTL-5b prior to i.p. injection with lethal dose of lipopolysaccharide (LPS)/D-galactosamine markedly reduced the levels of serum TNF- $\alpha$ and increased survival rates of animals from septic shock-induced death. Acute toxicity study using mice receiving increasing doses of UTL-5b showed that no animals were killed by UTL$5 \mathrm{~b}$ at $2,000 \mathrm{mg} / \mathrm{kg}\left(\mathrm{LD}_{50}>2,000 \mathrm{mg} / \mathrm{kg}\right)$. Our studies show that UTL-5b represents a novel anti-inflammatory and anti-arthritic agent with potential therapeutic application for RA treatment.
\end{abstract}

Keywords: carrageenan, collagen-induced arthritis, leflunomide, rheumatoid arthritis, TNF- $\alpha$. 


\section{Introduction}

Rheumatoid arthritis (RA) is the most common form of arthritis, a potentially crippling autoimmune disease that affects more than two million Americans. RA is a chronic disease that inflames joints and nearby areas [1, 2]. Besides the joints, other tissues can also be affected by RA. Abnormally high levels of tumor necrosis factor alpha (TNF- $\alpha$ ) have been detected in the rheumatoid joint, suggesting that TNF- $\alpha$ plays an important role in the pathology of RA. Earlier studies show that TNF- $\alpha$ is produced primarily by synovial tissue cells and activated macrophages and may contribute to a cytokine cascade with consequential increases in the levels of other inflammatory cytokines such as IL- $1 \alpha$. Further, $\mathrm{TNF}-\alpha$ may induce collagenase production that may contribute directly to cartilage destruction [3, 4]. These findings raise the possibility of therapeutic intervention in the cytokine cascade to control the potentially detrimental effect of RA.

There is no cure for RA and related diseases. Conventional treatments for RA patients include the use of non-steroidal anti-inflammatory drugs (NSAIDs). NSAIDs can relieve the pain and symptom of inflammation in RA patients but do not slow the progression of joint damage. Advances in recent years led to the discovery of disease-modifying anti-rheumatic drugs (DMARDs), such as cyclosporine, methotrexate and TNF- $\alpha$ antagonist, which can retard joint destruction by means of immunomodulation [1,58]. DMARDs can slow the disease progress and retard structural joint damage by preventing the immune system from attacking the joint. As a result, DMARDs are considered as an improved class of anti-arthritis drugs over traditional NSAIDs. Leflunomide (Arava ${ }^{\circledR}$ ) (Fig. 1) is a new type of isoxazole-containing heterocyclic DMARD approved by the FDA in 1998 for the treatment of moderate to severe RA [9-11]. One mechanism of action of leflunomide in suppressing inflammation is based on its inhibition of dihydroorotate dehydrogenase (DHODH), an enzyme responsible for de novo synthesis of pyrimidine. In addition, leflunomide has been shown to inhibit TNF- $\alpha$-induced NF- $\kappa B$, a potent mediator of inflammation. Upon absorption leflunomide is quickly metabolized to malononitrilamide (MNA or A771726) (Fig. 1) as the active therapeutic agent. MNA selectively inhibits DHODH and, thus, suppresses T-cell proliferation [12, 13]. Although effective, leflunomide can cause numerous side effects including liver toxicity and birth defect, preventing it from becoming a widely prescribed treatment of RA [14-17].

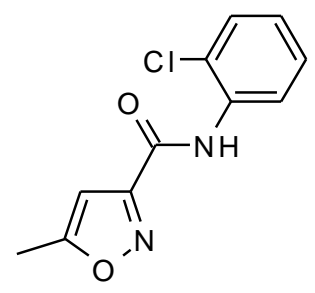

a. UTL-5b

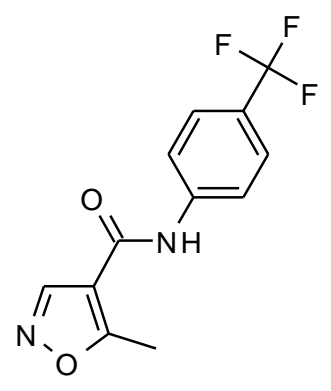

b. Leflunomide

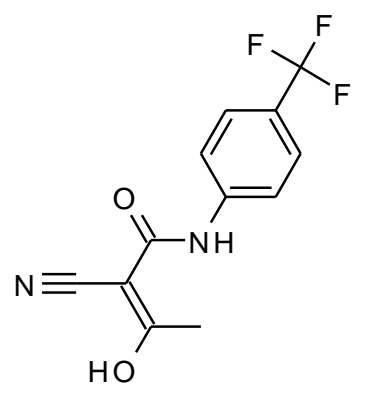

c. A771726 (MNA)

Fig. 1. Chemical structures of UTL-5b (a), leflunomide (b), and malononitrilamide (A771726) (c).

In this study, we investigated the antiinflammatory and anti-arthritic effects of a novel 
analogue of leflunomide, UTL-5b (Figure 1), for potential clinical application. We now report that treatment with UTL-5b can significantly reduce carrageenan-induced edema as well as type II collagen-induced arthritis (CIA) in animal models. Our results suggest that UTL-5b may act through the inhibition of TNF- $\alpha$ production in vivo. In addition, UTL-5b is well tolerated in animal study with low toxicity. Therefore, UTL-5b may represent a new class of anti-inflammatory agent with potential clinical application for patients with RA.

\section{Materials and Methods}

\subsection{Materials}

UTL-5b, leflunomide and its primary metabolite MNA (purity $>99 \%$ for all three compounds) were provided by laboratories of Drs. Huang and Lee. TNF- $\alpha$ and IL- $1 \alpha$ ELISA kits were purchased from Pierce/Endogen (Rockford, IL). The TNF- $\alpha$ kit has a sensitivity level of 18.2 $\mathrm{pg} / \mathrm{ml}$ and the IL- $1 \alpha$ ELISA kit has a sensitivity level of $6.00 \mathrm{pg} / \mathrm{ml}$. Anti-murine TNF- $\alpha$ and IL$1 \alpha$ monoclonal antibodies (mAbs) were obtained from PharMingen (San Diego, CA). LPS (E. Coli. 0111:B4) and other reagents were purchased from Sigma (St. Louis, MO).

\subsection{Animals}

Wistar albino rats (4-6 weeks) and ICR mice ( 8 weeks) were obtained from National Laboratory Animal Center, Taiwan. DBA/1 female mice (8-10 weeks) were obtained from Jackson Laboratories (Bar Harbor, ME). BALB/c female mice (8-10 weeks) were purchased from Taconic Farms (Germantown, NY). All animal studies were in full compliance with the Institutional Animal Care and Use Committee (IACUC) guidelines.

\subsection{Acute Toxicity Study}

Acute toxicity test based on the up-and-down procedure [18] was carried in male ICR mice (8 weeks). Mice were randomly divided into individual groups, 3-5 mice/group. In this test, every mouse was first injected i.p. with $250 \mathrm{mg} / \mathrm{kg}$ (default-starting dose) of the selected compound in liquid paraffin. If $>50 \%$ mice die or were moribund within $24 \mathrm{hrs}$, a second animal group was dosed at a lower dose of $200 \mathrm{mg} / \mathrm{kg}$. If no death was observed, increasing dose up to 2,000 $\mathrm{mg} / \mathrm{kg}$ (limit test) was then injected to the animal. If $>50 \%$ death was observed at limit test, the dose was reduced to $800 \mathrm{mg} / \mathrm{kg}$. Acute half lethal dose $\left(\mathrm{LD}_{50}\right)$ was determined after observing toxic reaction for three days.

\subsection{Carrageenan-induced Paw Edema Study}

Wistar albino rats (5 rats/group) were lightly anaesthetized under isofluorane and received a subplantar injection of $50 \mu \mathrm{l}$ saline containing $1 \%$ w/v carrageenan into the left hind footpad to initiate an acute inflammation. Sham operated group of rats received the same volume of vehicle at the same time. Paw volumes were determined using a water plethysmometer. Before injecting carrageenan, the volume of each left footpad was measured $\left(\mathrm{V}_{0}\right)$ as previously described $[19,20]$. Subsequent readings of the volume $\left(V_{t}\right)$ after injection were carried out at $0.5,1,2,3,4$ and $5 \mathrm{hr}$ and compared to the initial readings. To test the effect of UTL-5b, rats were treated with the compound by i.p. injection $(10 \mathrm{mg} / \mathrm{kg})$ one $\mathrm{hr}$ prior to the injection of carrageenan. Two additional groups of rats were treated with leflunomide and its metabolite (MNA) $(10 \mathrm{mg} / \mathrm{kg})$ as positive control. The edema (E \%) was calculated as follow:

$$
\mathrm{E}(\%)=\left[\left(\mathrm{V}_{\mathrm{t}}-\mathrm{V}_{0}\right) / \mathrm{V}_{0}\right] \times 100
$$

Where $\mathrm{V}_{\mathrm{t}}$ is the volume $(\mathrm{ml})$ of the rear left footpad at " $t$ " time after the injection of carrageenan. $\mathrm{V}_{0}$ is the volume $(\mathrm{ml})$ of the rear left footpad before the injection of carrageenan.

\subsection{Collagen-Induced Arthritis (CIA)}

Forty-five DBA/1 mice 8-10 weeks of age were injected with $100 \mu \mathrm{g}$ bovine type II collagen in Freund's complete adjuvant (FCA) intradermally at the base of the tail and monitored by daily examination for the onset of disease, which was recorded. At the first appearance of clinical evidence of arthritis, mice were divided randomly into one of three treatment groups: 1) $100 \mu \mathrm{l}$ sterile vehicle by oral gavage (o.g.) x 3 per week, 2) $100 \mu \mathrm{l}$ sterile vehicle containing UTL-5b 
at $30 \mathrm{mg} / \mathrm{kg}$ by o.g. x 3 per week, and 3) $100 \mu \mathrm{l}$ sterile vehicle containing UTL-5b at $60 \mathrm{mg} / \mathrm{kg}$ by o.g. x 3 per week.

The severity of arthritis in the affected paw was graded according to an established score system as follows: 0 (normal joint), 1 (mild/moderate visible edema and swelling), 2 (severe edema with distortion of paw and joint) and 3 (deformed paw or joint with ankylosis) [21]. The sum of the scores for all four paws in each mouse was used as an arthritis index (maximum score/mouse $=12$ ) to represent overall disease severity and progression in the animal. Animals were clinically assessed for disease five times per week until ten weeks after disease onset, and paw measurements were made three times per week. Arthritic paws without signs of disease at any time following treatment were considered in remission. All mice were pre-bled prior to the start of the trial, subsequently at onset of arthritis, two weeks post onset, four weeks post onset and at the completion of the trial. Sera obtained from each group were stored at $-80{ }^{\circ} \mathrm{C}$ until needed. ELISA assays were performed to determine total anticollagen antibody levels in mouse CIA.

\subsection{Effect of UTL-5b on the Production of TNF- $\alpha$ in LPS-treated Animal Model}

An animal model using BALB/c female mice treated with LPS was employed to study the effect of UTL-5b on the levels of serum TNF- $\alpha$ and IL$1 \alpha$ and the survival of animals after LPS-induced septic shock. UTL-5b was suspended in $1 \%$ carboxymethylcellulose before use. UTL-5b at doses of $30 \mathrm{mg} / \mathrm{kg}$ and $60 \mathrm{mg} / \mathrm{kg}$ per mouse was administered $o . g$. to fasting $\mathrm{BALB} / \mathrm{c}$ female mice 1 hour prior to i.p. injection of $50 \mu \mathrm{g}$ of LPS and $600 \mathrm{mg}$ of D-galactosamine (D-gal) per mouse in saline and the survival of the animals was monitored over the next 10 days [22]. Anti-murine TNF- $\alpha$ (1 mg/mouse) and IL- $1 \alpha$ mAbs (1 $\mathrm{mg} / \mathrm{mouse}$ ) were administered i.p. $6 \mathrm{~h}$ before LPS/D-gal injection to serve as positive controls for survival study. On day 5 of the experiment, all surviving mice were injected with a second dose of LPS/D-gal and survival was monitored for an additional five days. All surviving mice were sacrificed at the end of the experimental period. Blood from mice was collected by retro-orbital Am. J. Biomed. Sci. 2011, 3(1), 31-39; doi: 10.5099/aj110100031 bleeding 2 hours after the first LPS/D-gal injection for TNF- $\alpha$ and IL- $1 \alpha$ quantification using a commercial ELISA kit.

\section{Results}

\subsection{Acute Toxicity}

The symptoms of acute toxicity before death included agitation, lacrimation, trembling and reduced motility. The $\mathrm{LD}_{50}$ was determined to be $250 \mathrm{mg} / \mathrm{kg}$ and $200 \mathrm{mg} / \mathrm{kg}$ for leflunomide and MNA (A771726), respectively. Cyanosis and deep necrosis were noticed at death in mice receiving leflunomide and MNA between 1 and $12 \mathrm{hrs}$ after dosing. No animals were killed by UTL-5b at $2,000 \mathrm{mg} / \mathrm{kg}$. No further attempts were made to determine the $\mathrm{LD}_{50}$ for UTL-5b. The only symptom observed at this dose was "agitation" in day one during the three-day testing period.

\subsection{Carrageenan-induced Edema Study}

A carrageenan-induced edema animal model was used to examine the anti-inflammatory activity of UTL-5b. Carrageenan-induced inflammation was associated with a rapid swelling of the paw with an increase in volume of $>20 \%$ within $1 \mathrm{hr}$ and reached a maximum $(64.5 \%)$ at 5 hr (Fig. 2). Treatment with UTL-5b (10 mg/kg) i.p. one hr prior to carrageenan injection greatly reduced paw edema from $64.5 \%$ to less than $15 \%$ $(14.4 \%)$ at $5 \mathrm{hr}$. In contrast, treatment with leflunomide and its metabolite, MNA, at the same dose reduced the edema to $34.8 \%$ and $24.2 \%$, respectively.

\subsection{Effect of UTL-5b on Collagen-Induced Arthritis}

A mouse CIA model was used to examine the anti-arthritis effect of UTL-5b. The progression of arthritis in mice treated $o . g$. with the UTL-5b at 30 $\mathrm{mg} / \mathrm{kg}$ and $60 \mathrm{mg} / \mathrm{kg}$ is shown in Fig. 3a. There was a marked effect of UTL-5b when compared with the saline control group after one week of treatment. A significant reduction $(\mathrm{p}=0.03)$ in the arthritic score in mice treated with $30 \mathrm{mg} / \mathrm{kg}$ was seen after one week and this reduction became highly significant $(\mathrm{p}<0.001)$ after three weeks. However, the difference between the $30 \mathrm{mg} / \mathrm{kg}$ group and control ceased to be significant after week 5, with the exception of week $9(\mathrm{p}<0.015)$. A

(C) 2011 by NWPII. All rights reserved. 
significant reduction $(\mathrm{p}=0.03)$ in the clinical score in mice treated with $60 \mathrm{mg} / \mathrm{kg}$ was seen after two weeks, and this reduction became highly significant $(p<0.001)$ after three weeks and remained significant throughout the remainder of the trial.

The number of arthritic paws (Figure 3b) in mice treated with UTL- $5 \mathrm{~b}$ at $30 \mathrm{mg} / \mathrm{kg}$ was significantly reduced below the level in the control group at 3 weeks $(\mathrm{p}<0.03)$, but this reduction was not statistically significant thereafter. In contrast, mice treated with UTL- $5 \mathrm{~b}$ at $60 \mathrm{mg} / \mathrm{kg}$ showed a significant reduction $(\mathrm{p}<0.02)$ in the number of arthritic paws after three weeks and achieved a highly significant difference $(\mathrm{p}<0.005)$ by week 7 . The arthritic paw count in this group was significantly lower compared with the saline control throughout the trial, although the significance at termination (week 10) was reduced $(\mathrm{p}<0.05)$.

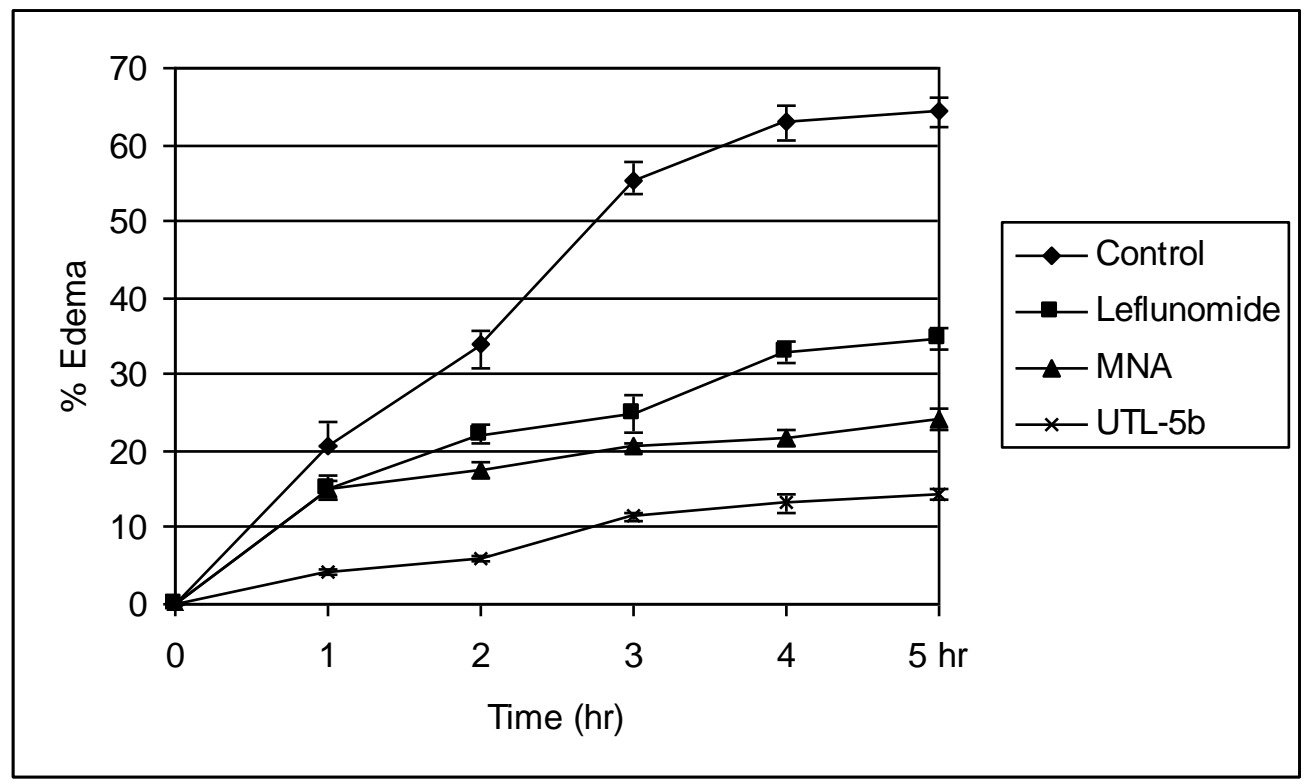

Fig. 2. Effect of UTL-5b on carrageenan-induced hind paw edema. Twenty Wistar rats were randomly divided into 4 groups. Animals were treated with UTL-5b, leflunomide and its active metabolite MNA (A771726) (10 mg/kg) i.p. one $\mathrm{hr}$ prior to carrageenan $(1 \% \mathrm{w} / \mathrm{v} 50 \mu \mathrm{l})$ injection into the left hind footpad. Control rats received vehicle only. Increase in paw volumes was determined using a water plethysmometer. Each value represents the mean \pm S.D. of 5 animals. $\mathrm{p}<0.02$, UTL-5b vs. control; $\mathrm{p}<0.01$, UTL-5b vs. leflunomide; $\mathrm{p}<0.01$, UTL-5b vs. MNA.

The effect of UTL-5b on anti-type II antibody levels was examined using ELISA assay. All animals developed anti-type II collagen antibody at onset of arthritis. The levels of total anti-type II collagen antibody were slightly lower in mice treated with UTL-5b as compared with control mice without treatment (data not shown). The difference, however, was not statistically significant in all cases.

\subsection{Effect of UTL-5b on the Production of TNF- $\alpha$ in LPS-Treated Animal Model}

Since TNF- $\alpha$ is one of the primary inflammatory cytokines responsible for the arthritis, we asked if the anti-inflammatory and Am. J. Biomed. Sci. 2011, 3(1), 31-39; doi: 10.5099/aj110100031 anti-arthritic effects of UTL-5b are mediated through the modulation of TNF- $\alpha$ production. A septic shock animal mode induced with LPS/D-gal was used to examine the effect of UTL-5b on blood levels of TNF- $\alpha$ [22]. Treatment of the animals with LPS/D-gal dramatically increased the levels of serum TNF- $\alpha$ in control $(<9 \mathrm{ng} / \mathrm{ml})$ to more than $500 \mathrm{ng} / \mathrm{ml}$ within $2 \mathrm{hr}$. Animals receiving UTL-5b by o.g. one hr prior to LPS/Dgal treatment showed significantly reduction of TNF- $\alpha$ levels in a dose-dependent manner (reduction of $58 \%$ at $30 \mathrm{mg} / \mathrm{kg}$ and $73 \%$ at 60 $\mathrm{mg} / \mathrm{kg}$ as compared to controls) (Fig. 4a). Unlike leflunomide, however, UTL-5b did not

(C) 2011 by NWPII. All rights reserved. 
significantly reduce levels of IL-1 $\alpha$ (Fig. 4b). All animals treated with LPS/D-gal alone died within 5 days as a result of the septic shock. In animals receiving UTL-5b prior to LPS/D-gal treatment, the survival rates were significantly increased as compared to those in the control group $(42.8 \%$ and $57.1 \%$ survival at $30 \mathrm{mg} / \mathrm{kg}$ and $60 \mathrm{mg} / \mathrm{kg}$, respectively) (Fig. 4c). A survival rate of $90 \%$ was observed in animals that had been treated with anti-TNF- $\alpha$ /anti-IL-1 $\alpha$ mAbs prior to LPS/D-gal treatment.

$3 a$.

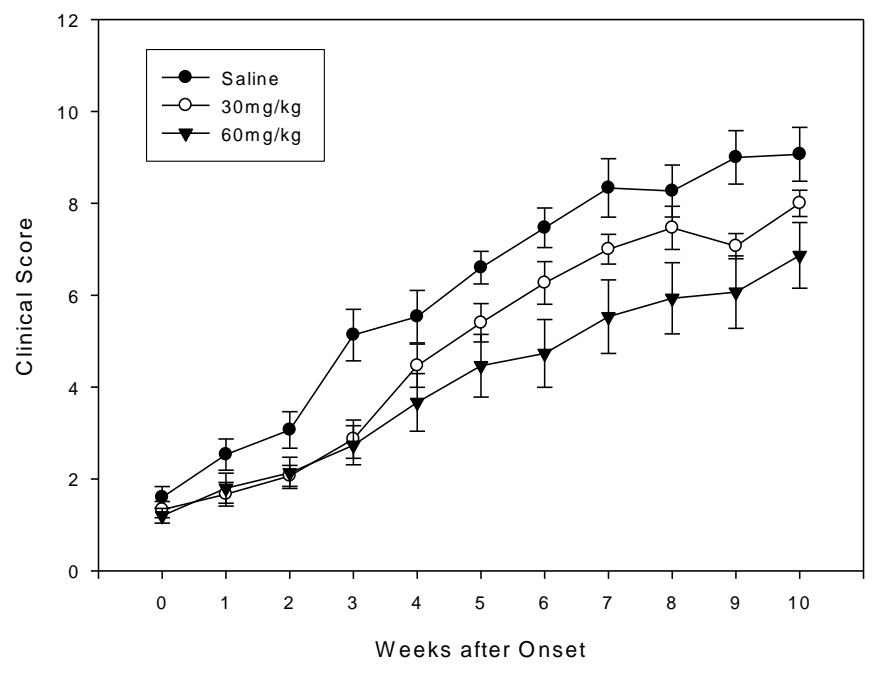

$3 b$.

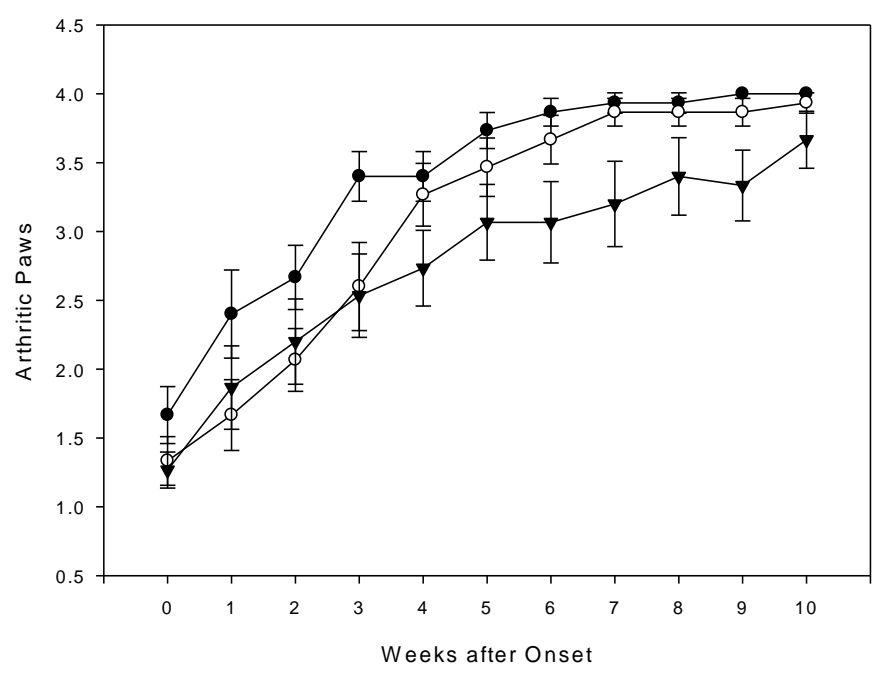

Fig. 3. Effects of UTL-5b on arthritis score (a) and arthritic paw count (b) in CIA mouse model. Forty-five $\mathrm{DBA} / 1$ mice were randomly divided into 3 groups. Mice were immunized with type II collagen/CFA Am. J. Biomed. Sci. 2011, 3(1), 31-39; doi: 10.5099/aj110100031 mixture by intradermal injection at the base of the tail of the animals. Treatment started at the first appearance of clinical evidence of arthritis with UTL-5b o.g. x 3 per week at $30 \mathrm{mg} / \mathrm{kg} /$ day and $60 \mathrm{mg} / \mathrm{kg} / \mathrm{day}$, respectively. Control received saline only. Results are shown as the mean \pm S.D. $(n=15)$.

\section{Discussion}

RA is a common disease characterized by chronic inflammation and irreversible destruction of articular cartilage and bone [2, 4]. At present, there is no cure for RA. Leflunomide is the first isoxazole-containing DMARD approved for RA treatment. Although effective in reducing joint inflammation and destruction in clinical trials, leflunomide has numerous undesirable side effects preventing it from becoming a widely prescribed treatment of RA [14-17]. In this study, we examined the anti-inflammatory and anti-arthritic effects of a novel analogue of leflunomide, UTL$5 \mathrm{~b}$. We showed that pretreatment of the animals with UTL-5b can significantly reduce carrageenan-induced edema in animal model. The reduction of edema formation was remarkable compared to that with leflunomide at the same dose used in this study. This finding establishes that UTL-5b has in vivo anti-inflammatory activity.

To investigate the anti-arthritic effect of UTL5b, a mouse CIA model was used [21]. The antiarthritis effect of UTL-5b is dose-dependent, with mice given $30 \mathrm{mg} / \mathrm{kg} \mathrm{o.g}$. exhibiting amelioration of disease early in the test but losing statistical significance over time. In contrast, mice treated with $60 \mathrm{mg} / \mathrm{kg}$ showed sustained anti-arthritis effect over the ten week trial period. Mice treated with UTL-5b at $60 \mathrm{mg} / \mathrm{kg}$ also showed a significant reduction $(p<0.02)$ in the number of arthritic paws after three weeks and achieved a highly significant difference $(\mathrm{p}<0.005)$ by week 7 . Thus, a dose of $60 \mathrm{mg} / \mathrm{kg}$ or more is needed to achieve a sustaining therapeutic effect in arthritic animals. Interestingly, investigation on the levels of anti-type II collagen antibody did not indicate any marked effect. The levels of total anti-type II collagen antibody were lowered slightly by UTL$5 \mathrm{~b}$ treatment; the difference, however, was not statistically significant. This finding suggests that

(C) 2011 by NWPII. All rights reserved. 
the effect of UTL-5b may not be mediated through antibody modulation. Given that UTL-5b is relatively non-toxic $\left(\mathrm{LD}_{50}>2,000 \mathrm{mg} / \mathrm{kg}\right.$ ) as compared to leflunomide $\left(\mathrm{LD}_{50}=250 \mathrm{mg} / \mathrm{kg}\right)$, there is potential for UTL-5b to achieve a greater therapeutic effect by extended treatment at higher doses. 4a.

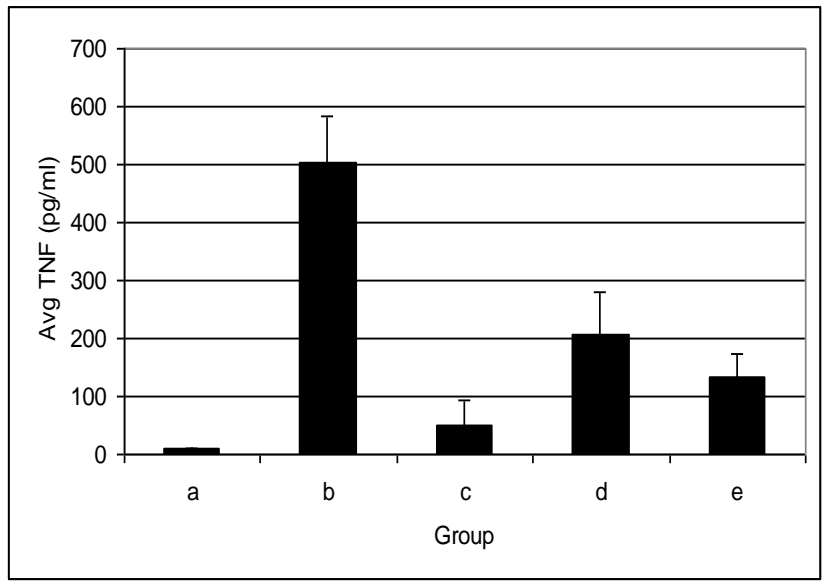

4b.

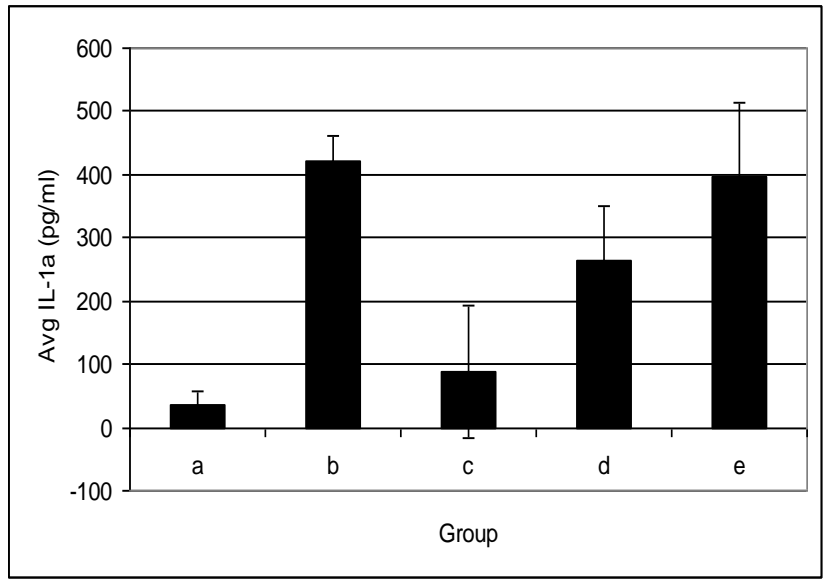

4c.

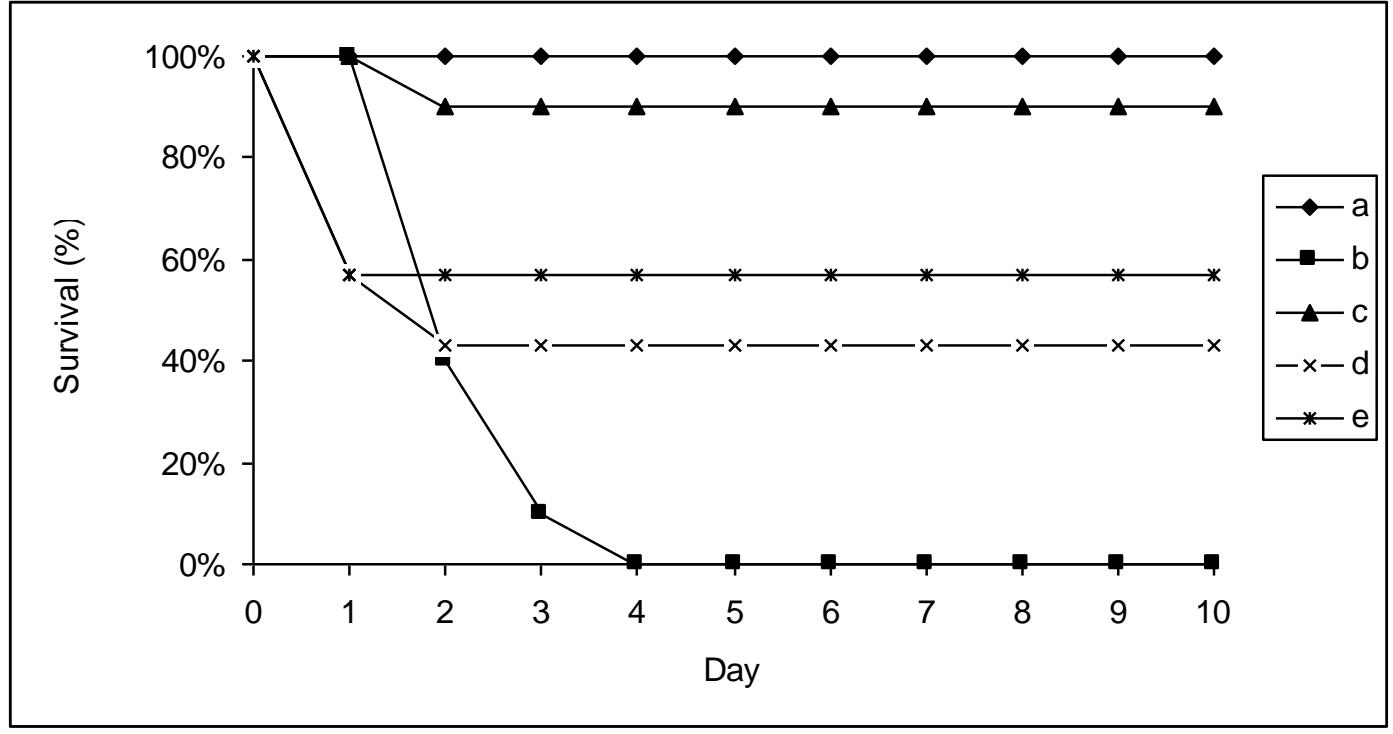

Fig. 4. Effect of UTL-5b on the levels of serum TNF- $\alpha$ (a) and IL-1 $\alpha$ (b) and the survival of mice (c) in a septic shock animal model. BALB/c female mice (7-10 mice/group) were randomly divided into 5 groups and were treated as follows: a) No treatment (vehicle only); b) LPS/D-gal; c) $1 \mathrm{mg} / \mathrm{mouse}$ of anti-TNF- $\alpha /$ anti-IL-1 $\alpha$ mAbs $6 \mathrm{hr}$ prior to LPS/D-gal injection; d) $30 \mathrm{mg} / \mathrm{kg}$ of UTL-5b o.g. $1 \mathrm{hr}$ prior to LPS/D-gal injection; and e) $60 \mathrm{mg} / \mathrm{kg}$ of UTL-5b o.g. 1 $\mathrm{hr}$ prior to LPS/D-gal injection. TNF- $\alpha / \mathrm{IL}-1 \alpha$ concentration ( $\mathrm{pg} / \mathrm{ml} \pm$ S.D.) is the average of 10 mice for groups $\mathrm{a}, \mathrm{b}$, and $c$ and the average of 7 mice for groups $d$ and e. For 4a, Student's t-test was performed and all $p$ values $<0.05$ for the following groups: $b$ and $a ; c$ and $b ; d$ and b; e and $b$. For $4 b, b$ and a, p < 0.05; $c$ and b, p < 0.05; d and b, p > 0.05; $\mathrm{e}$ and $\mathrm{b}, \mathrm{p}>0.05$. Blood was collected by retro-orbital bleeding 2 hours after the first LPS/D-gal injection for TNF- $\alpha$ and IL-1 $\alpha$ quantification. 
It is well established that TNF- $\alpha$, although not the primary culprit of RA, plays an important role in the pathology of RA [3-5]. TNF- $\alpha$ can induce collagenase production that may contribute directly to cartilage destruction and bone resorption. Using a mouse model treated with lethal dose of LPS, we showed that UTL-5b is a potent inhibitor of TNF- $\alpha$ production in vivo. However, unlike leflunomide, UTL-5b does not significantly reduce the levels of IL- $1 \alpha$ suggesting that the action of UTL-5b is different from that of leflunomide [23]. The anti-TNF- $\alpha$ effect is consistent with the finding that by lowering the levels TNF- $\alpha$, UTL-5b can significantly increase the survival rate of animals in septic shockinduced death. All surviving animals had much lower levels of TNF- $\alpha$ with UTL-5b treatment compared with non-treated controls.

In summary, we showed that UTL-5b is an effective anti-inflammation and anti-arthritis agent. The action of UTL-5b appears to be mediated through the reduction of TNF- $\alpha$ in vivo and may be the contributing factor to the amelioration of arthritis seen in the animal model. UTL-5b is relatively non-toxic and can be administered orally, but the potential side effects and long-term toxicity of UTL-5b will need to be studied in the future. Our findings suggest that UTL-5b may be a much safer substitute of leflunomide for the treatment of RA.

\section{Acknowledgements}

This work was supported in part by NIH grant R43AR052193.

Abbreviation: CIA, collagen-induced arthritis; DHODH, dihydroorotate dehydrogenase; D-gal, D-galactosamine; DMARDs, disease-modifying anti-rheumatic drugs; IL-1 $\alpha$, interleukin-1 alpha; LPS, lipopolysaccharide, MNA (A771726), malononitrilamide; RA, rheumatoid arthritis; TNF- $\alpha$, tumor necrosis factor alpha.

\section{References}

1. Wollheim, F.A., Approaches to rheumatoid arthritis in 2000. Curr Opin Rheumatol, 2001. 13(3): p. 193-201.

2. Rewatkar, P.V., et al., Rheumatoid arthritis: a new challenge in coming era. Mini Rev Med Chem, 2010. 10(2): p. 98-107.

3. Alvaro-Gracia, J.M., N.J. Zvaifler, and G.S. Firestein, Cytokines in chronic inflammatory arthritis. $V$. Mutual antagonism between interferon-gamma and tumor necrosis factoralpha on HLA-DR expression, proliferation, collagenase production, and granulocyte macrophage colony-stimulating factor production by rheumatoid arthritis synoviocytes. J Clin Invest, 1990. 86(6): p. 1790-8.

4. Migita, K., et al., TNF-alpha-mediated expression of membrane-type matrix metalloproteinase in rheumatoid synovial fibroblasts. Immunology, 1996. 89(4): p. 5537.

5. Maini, R.N. and P.C. Taylor, Anti-Cytokine Therapy for Rheumatoid Arthritis. Annual Review of Medicine, 2000. 51(1): p. 207-229.

6. Shanahan, J.C. and W. St Clair, Tumor necrosis factor-alpha blockade: a novel therapy for rheumatic disease. Clin Immunol, 2002. 103(3 Pt 1): p. 231-42.

7. Criscione, L.G. and E.W. St Clair, Tumor necrosis factor-alpha antagonists for the treatment of rheumatic diseases. Curr Opin Rheumatol, 2002. 14(3): p. 204-11.

8. Smolen, J.S., et al., New therapies for treatment of rheumatoid arthritis. Lancet, 2007. 370(9602): p. 1861-74.

9. Cutolo, M., et al., Anti-inflammatory effects of leflunomide on cultured synovial macrophages from patients with rheumatoid arthritis. Ann Rheum Dis, 2003. 62(4): p. 297-302.

10. Goldenberg, M.M., Leflunomide, a novel immunomodulator for the treatment of active rheumatoid arthritis. Clin Ther, 1999. 21(11): p. 1837-52; discussion 1821.

11. Breedveld, F.C. and J.M. Dayer, Leflunomide: mode of action in the treatment of rheumatoid arthritis. Ann Rheum Dis, 2000. 59(11): p. 841-9. 
12. Cherwinski, H.M., et al., The immunosuppressant leflunomide inhibits lymphocyte proliferation by inhibiting pyrimidine biosynthesis. J Pharmacol Exp Ther, 1995. 275(2): p. 1043-9.

13. Davis, J.P., et al., The immunosuppressive metabolite of leflunomide is a potent inhibitor of human dihydroorotate dehydrogenase. Biochemistry, 1996. 35(4): p. 1270-3.

14. Kaplan, M.J., Leflunomide Aventis Pharma. Curr Opin Investig Drugs, 2001. 2(2): p. 22230.

15. Osiri, M., et al., Leflunomide for the treatment of rheumatoid arthritis: a systematic review and metaanalysis. J Rheumatol, 2003. 30(6): p. 1182-90.

16. Sanders, S. and V. Harisdangkul, Leflunomide for the treatment of rheumatoid arthritis and autoimmunity. Am J Med Sci, 2002. 323(4): p. 190-3.

17. Turkoski, B.B., Rheumatoid arthritis and the Arava (leflunomide) controversy. Orthop Nurs, 2003. 22(1): p. 48-51.

18. NIH, The Revised Up-and-Down Procedure: A Test Method for Determining the Acute Oral
Toxicity of Chemicals. NIH Publication No. 02-4501, 2001. Volumes 1 and 2.

19. Huang, W.H., et al., Leflunomide analogues as potential antiinflammatory agents. Chem Pharm Bull (Tokyo), 2003. 51(3): p. 313-4.

20. Winter, C.A., E.A. Risley, and G.W. Nuss, Carrageenin-induced edema in hind paw of the rat as an assay for antiiflammatory drugs. Proc Soc Exp Biol Med, 1962. 111: p. 544-7.

21. Wooley, P.H., et al., Type II collagen-induced arthritis in mice. I. Major histocompatibility complex (I region) linkage and antibody correlates. J Exp Med, 1981. 154(3): p. 688700.

22. Endo, Y., et al., Enhancement by galactosamine of lipopolysaccharide(LPS)induced tumour necrosis factor production and lethality: its suppression by LPS pretreatment. Br J Pharmacol, 1999. 128(1): p. 5-12.

23. Yao, H.W., et al., Effect of leflunomide on immunological liver injury in mice. World $\mathrm{J}$ Gastroenterol, 2003.9(2): p. 320-3. 